paper "On a New Kind of Rays" from the Sitzungsberichte der Würzburger Gesellschaft, 1895, which appeared in the same issue. This, we believe, was the first complete account of Röntgen's work published in England. To the same issue (Jan. 23, p. 276) the late Mr. A. A. Campbell Swinton contributed an article describing how, "Working upon the lines indicated in the telegrams from Vienna, recently published in the daily papers, I have, with the assistance of Mr. J. C. M. Stanton, repeated many of Prof. Röntgen's experiments with entire success "; and his article was illustrated by an X-ray photograph of a human hand taken by him with a Crookes tube. In the following three months as many as one hundred and fifty-five notes and original communications upon X-rays and their applications appeared in our columns.

\section{Gold Medal for Astronomy}

THE award of the gold medal of the Royal Astronomical Society to Dr. R. G. Aitken, director of the Lick Observatory, Mount Hamilton, California, was the subject of the presidential address given by Dr. Knox-Shaw, Radcliffe Observer, Oxford, at the annual general meeting of the Society on Feb. 12. The actual presentation of the medal is deferred until May 13, when the medallist is coming to London to deliver the George Darwin lecture; the subject of this has not yet been announced, but it will probably be connected with double stars. Dr. Knox-Shaw began his address by giving a description of the state of double-star astronomy in the middle of the last century ; it was taken for granted that the work of the two Herschels and the two Struves had exhausted the mine of possible discoveries, at least in the northern hemisphere, and that it only remained to continue the observation of the known pairs, with a view of obtaining better orbits.

\section{Dr. Aitken and other Double-Star Observers}

WiтH the advent of the great American telescopes a new era began. It became possible to detect much closer pairs than before; these offered such a large field that for the first time a distance limit was fixed, beyond which stars should not rank as doubles. This was taken as $5^{\prime \prime}$ for stars of the ninth magnitude, but was made wider for brighter stars and for stars of large common proper motion. S. W. Burnham was the first to make a great advance in this direction; in 1906 he brought out a great catalogue of 13,665 pairs, more than two thousand of these being his own discoveries. Dr. Aitken has been a worthy successor. With the aid of Dr. Hussey, who was his fellowworker for many years, about four thousand new pairs have been found, and a new general catalogue is in course of formation. An important point is that many of the new pairs are extremely close (separation less than half a second). As was to be expected, many of these close pairs showed fairly rapid motion ; in fact, one of them has completed a revolution since discovery; Dr. Aitken enjoys the distinction of having made all the observations upon it, and also of computing its orbit. From a physical point of view, the chief importance of double-star astronomy is the information that it leads to on the masses of the stars. At the beginning of this century not more than a dozen star-masses were known with any accuracy; the number has now been greatly increased, the study of eclipsing binaries having added to it. As a result, Sir Arthur Eddington was able to deduce the law correlating mass with absolute magnitude. This important law rests largely on such work as that carried on by Dr. Aitken.

\section{Gold Medal of the Hunterian Society}

THE Hunterian Society, the oldest medical society in London, offers annually or periodically for competition a medal bearing the profile of John Hunter. It is open to all general medical practitioners resident in Great Britain, Ireland, and the Channel Islands, and is awarded for an essay. The subject of the essay is chosen by the writers from any subject in the medical sciences, and each essay has to be written under a motto or device and is accompanied by a sealed envelope containing the writer's name. In 1931 the Council recommended that the medal should be of gold instead of silver as heretofore, and that a new design should be struck. Accordingly, Mr. Thornton Shiells, with Mr. H. Youngman, engraver, produced a gold medal the size of a crown piece. The original designs and the plaster medallion made for the purpose are now preserved in the Library of the Society. For the first competition under the new régime a number of essays of high order were received, and the medal has been awarded to Dr. Griffith Ifor Exvans, 37 Castle Square, Caernarvon, for an essay on "Chronic Familial Syphilis". Dr. Gwladys Victoria Smallpiece, of 365 Woodstock Road, Oxford, was declared " proxime accessit". The medal was presented to Dr. Griffith Evans at the annual dinner on Feb. 11. The next award of the gold medal will be made in 1933 for essays received on or before Dec. 31, 1932. The rules governing the award may be obtained on application to the honorary secretary of the Society, Mr. Andrew McAllister, 79 Wimopole Street, London, W.1.

\section{Extension of University College, London}

UnIversity College, London, has acquired by purchase a site of two acres, formerly occupied by Messrs. Shoolbred, immediately south of the buildings of the Faculty of Medical Sciences of the College. This is the largest addition to the site of the College made since its foundation more than one hundred years ago. The site acquired by the founders was some eight acres in extent, and most of the previous additions to the College have been confined to this area. So long as fifty years ago attempts were made by the College to buy the site, on which, eventually, were erected warehouses, depositories, and stables for Messrs. Shoolbred. The site was too large for University College to buy or to occupy as a whole. The problem was solved by the Carnegie United Kingdom Trustees, who acquired part of the property as permanent headquarters for the National Central Library and the Library Association. In the College part of the territory there will be housed the Departments of

No. 3251, VoL. 129$]$ 